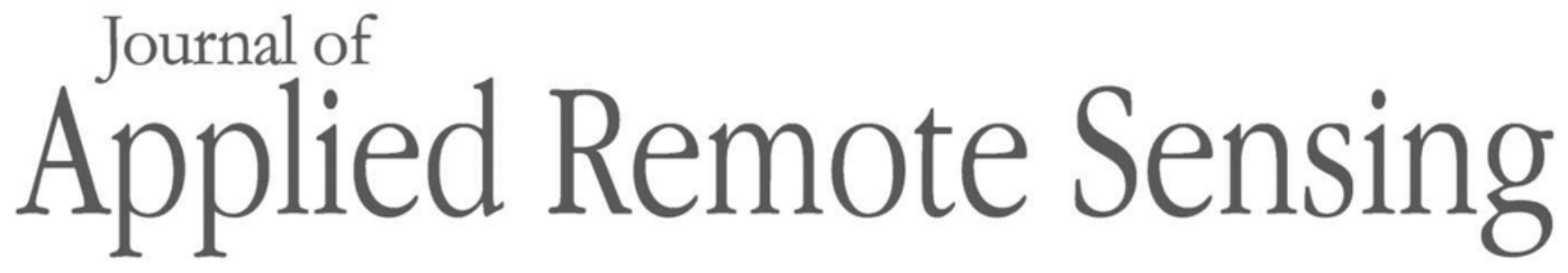

RemoteSensing.SPIEDigitalLibrary.org

\title{
Satellite-based land use mapping: comparative analysis of Landsat-8, Advanced Land Imager, and big data Hyperion imagery
}

\author{
Wasim Pervez \\ Vali Uddin \\ Shoab Ahmad Khan \\ Junaid Aziz Khan
}




\title{
Satellite-based land use mapping: comparative analysis of Landsat-8, Advanced Land Imager, and big data Hyperion imagery
}

\author{
Wasim Pervez, ${ }^{\mathrm{a}, *}$ Vali Uddin, ${ }^{\mathrm{b}}$ Shoab Ahmad Khan, ${ }^{\mathrm{a}}$ and \\ Junaid Aziz Khan ${ }^{\text {a }}$ \\ ${ }^{a}$ National University of Sciences and Technology, H-12, 44000 Islamabad, Pakistan \\ ${ }^{\mathrm{b}}$ Hamdard University, 74200 Karachi, Pakistan
}

\begin{abstract}
Until recently, Landsat technology has suffered from low signal-to-noise ratio (SNR) and comparatively poor radiometric resolution, which resulted in limited application for inland water and land use/cover mapping. The new generation of Landsat, the Landsat Data Continuity Mission carrying the Operational Land Imager (OLI), has improved SNR and high radiometric resolution. This study evaluated the utility of orthoimagery from OLI in comparison with the Advanced Land Imager (ALI) and hyperspectral Hyperion (after preprocessing) with respect to spectral profiling of classes, land use/cover classification, classification accuracy assessment, classifier selection, study area selection, and other applications. For each data source, the support vector machine (SVM) model outperformed the spectral angle mapper (SAM) classifier in terms of class discrimination accuracy (i.e., water, built-up area, mixed forest, shrub, and bare soil). Using the SVM classifier, Hyperion hyperspectral orthoimagery achieved higher overall accuracy than OLI and ALI. However, OLI outperformed both hyperspectral Hyperion and multispectral ALI using the SAM classifier, and with the SVM classifier outperformed ALI in terms of overall accuracy and individual classes. The results show that the new generation of Landsat achieved higher accuracies in mapping compared with the previous Landsat multispectral satellite series. (C) The Authors. Published by SPIE under a Creative Commons Attribution 3.0 Unported License. Distribution or reproduction of this work in whole or in part requires full attribution of the original publication, including its DOI. [DOI: 10.1117/1.JRS.10.026004]
\end{abstract}

Keywords: Landsat-8; Operational Land Imager; Hyperion; hyperspectral; principal component analysis; classification accuracy.

Paper 15742 received Nov. 1, 2015; accepted for publication Mar. 15, 2016; published online Apr. 7, 2016.

\section{Introduction}

A new generation of Landsat [Landsat-8 Operational Land Imager (OLI)] was launched in 2013. Landsat- 8 uses reflective windows, namely OLI, and thermal atmospheric windows, i.e., Thermal Infrared Scanner (TIRS), to explore Earth phenomenology. ${ }^{1} \mathrm{OLI}$ is a push-broom sensor that collects imagery in eight spectral bands with $30 \mathrm{~m}$ resolution. It allows for 12-bit quantization of data, which have high signal-to-noise (SNR) radiometric performance and provide more bits for land use/cover mapping. ${ }^{2}$ In OLI, a new coastal/aerosol band is centered at $443 \mathrm{~nm}$, and its enhanced features should allow for more accurate water and land use/cover mapping compared with the previous Landsat series. ${ }^{3-5}$ For example, Landsat-7, which was characterized by 8-bit quantization and low SNR performance, which made it difficult to separate water from other dark objects.

Aside from the Landsat series, other comparable satellite-based sensors include the Advanced Land Imager (ALI), Hyperion, and IKONOS. ALI is a push-broom sensor that collects imagery in nine spectral bands with $30 \mathrm{~m}$ resolution. It has higher SNR, radiometric reliability, and spectral channels than Landsat-7. ${ }^{6}$ For Hyperion, the bands and resolution of imagery allow for 12-bit quantization of data; however, limitations in the system design result in low SNR performance

*Address all correspondence to: Wasim Pervez, E-mail: wasim_pervaiz@pnec.nust.edu.pk 
in very short blue bands and the need for atmospheric correction in preprocessing. ${ }^{78}$ IKONOS QuickBird imagery has been used for water mapping in shallow waters but is not useful for regular monitoring purposes ${ }^{9-11}$ and was not considered in this study.

Hyperspectral remote sensing with narrow spectral bands is appropriate for analyzing inland waters and land cover mapping/change. ${ }^{12-18}$ In particular, the Hyperion sensors used for land use/cover classification can capture 256 spectra, each with 242 narrow electromagnetic bands, including visible and shortwave-infrared. ${ }^{19-27}$ However, few studies have examined the use of previous Landsat multispectral satellite series in land use/cover mapping applications. ${ }^{17,18,28,29}$

In addition to the different sensors, the classification of remote sensing imagery can employ both parametric and nonparametric classifiers, for example, the spectral angle mapper (SAM) ${ }^{30,31}$ and the support vector machine (SVM). ${ }^{32,33}$ The SAM classifier is noniterative, ${ }^{34}$ whereas SVM is an iterative classifier that is independent of the statistical data distribution and study training data near the class border. ${ }^{35,36}$

This study compared the enhanced capabilities of the new generation of Landsat (Landsat-8 OLI), with the interpretation, display, and analysis of data from the ALI and Hyperion sensors. The main purposes of the study were (1) to analyze the application of fast line-of-sight atmospheric analysis of hypercubes (FLAASH) and quick atmospheric correction (QUAC) to OLI, ALI, and Hyperion orthoimagery following preprocessing and the application of principal component analysis (PCA); (2) to evaluate the spectral profiling of all classes from OLI, ALI, and Hyperion orthoimagery; (3) to evaluate the classification of OLI, ALI, and Hyperion orthoimages using the SVM and SAM classifiers; and (4) to compare the classification accuracies of OLI, ALI, and hyperspectral Hyperion orthoimages using SVM and SAM techniques.

\section{Study Area, Sensors, and Data Characteristics}

This study focused on dam water in a region northwest of Islamabad, Pakistan (Fig. 1). The region of interest included water, built-up-area, mixed forest, shrub, and bare soil. The sensor

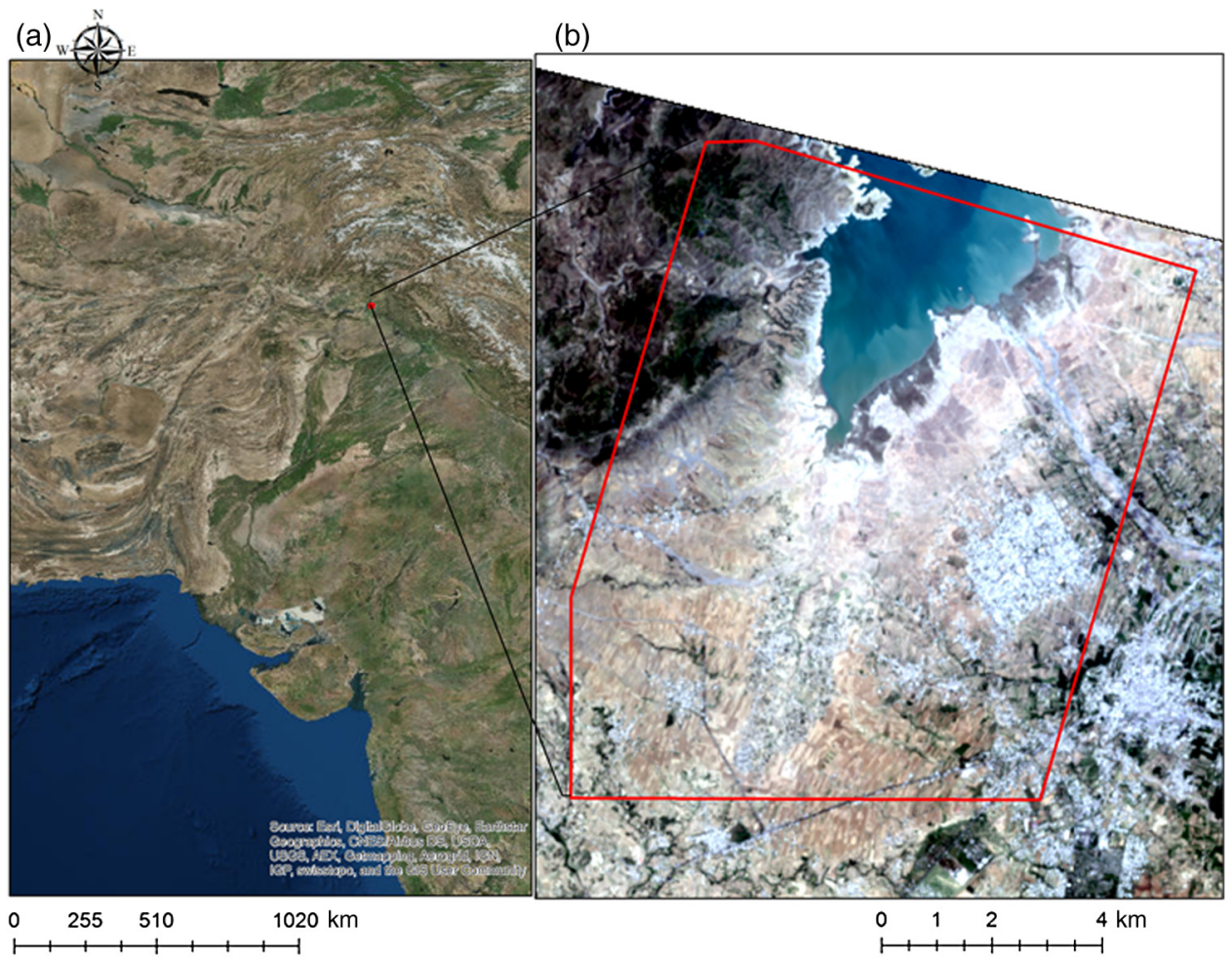

Fig. 1 (a) Regional location of the study area, located northwest of Islamabad, Pakistan, and (b) satellite image of the study area (enclosed in red box). 
Pervez et al.: Satellite-based land use mapping: comparative analysis of Landsat-8...

Table 1 Imaging geometry conditions for Landsat-8, ALI, and Hyperion.

\begin{tabular}{lccc}
\hline \hline & Landsat-8 OLI & ALI & Hyperion \\
\hline Sensor altitude $(\mathrm{km})$ & 705 & 705 & 705 \\
Off-nadir/Nadir & Nadir & $16.216 \mathrm{deg}$ & $23.412 \mathrm{deg}$ \\
Sun azimuth & $111.553 \mathrm{deg}$ & $155.544 \mathrm{deg}$ & $155.039 \mathrm{deg}$ \\
Sun elevation & $68.452 \mathrm{deg}$ & $42.866 \mathrm{deg}$ & $45.812 \mathrm{deg}$ \\
\hline \hline
\end{tabular}

altitudes of Landsat-8 OLI, ALI, and Hyperion were the same (Table 1). The Landsat-8 OLI line of sight was at nadir, while there were slight differences in the line of sight for ALI and Hyperion; therefore, ALI did not exactly image the Hyperion swath. Landsat- 8 contains 11 bands, with wavelengths ranging from 433 to $12,500 \mathrm{~nm}$, ground resolution of 15 to $100 \mathrm{~m}$, and a swath width of $185 \mathrm{~km}$ (Table 2) ${ }^{37}$ ALI contains nine bands, with wavelengths ranging from 480 to $2350 \mathrm{~nm}$, ground resolution of 10 to $30 \mathrm{~m}$, and a swath width of $37 \mathrm{~km} .{ }^{38}$ Hyperion sensors contain 70 bands in the visible-near-infrared (VNIR; 355 to 1057) and

Table 2 Characteristics of multispectral Landsat 8, multispectral ALI, and Hyperion hyperspectral sensors. $^{37-39}$

\begin{tabular}{|c|c|c|c|c|c|}
\hline Sensors & Band name & Band number & Wavelength (nm) & Ground resolution (m) & Swath width $(\mathrm{km})$ \\
\hline \multirow[t]{10}{*}{ Landsat-8 } & $\begin{array}{c}\text { Coastal/Aerosol } \\
\text { Blue }\end{array}$ & $\begin{array}{l}1 \\
2\end{array}$ & $\begin{array}{l}433 \text { to } 453 \\
450 \text { to } 515\end{array}$ & 30 & 185 \\
\hline & Green & 3 & 525 to 600 & & \\
\hline & Red & 4 & 630 to 680 & & \\
\hline & NIR & 5 & 845 to 885 & & \\
\hline & SWIR-1 & 6 & 1560 to 1660 & & \\
\hline & SWIR-2 & 7 & 2100 to 2300 & & \\
\hline & Pan & 8 & 500 to 680 & 15 & \\
\hline & Cirrus & 9 & 1360 to 1390 & 30 & \\
\hline & TIR-1 & 10 & 10,300 to 11,300 & 100 & \\
\hline & TIR-2 & 11 & 11,500 to 12,500 & & \\
\hline \multirow[t]{8}{*}{ ALI } & $\begin{array}{l}\text { Pan } \\
\text { Blue } \\
\text { Blue1 }\end{array}$ & $\begin{array}{c}10 \\
1 \\
2\end{array}$ & $\begin{array}{l}480 \text { to } 690 \\
433 \text { to } 453 \\
450 \text { to } 515\end{array}$ & $\begin{array}{l}10 \\
30\end{array}$ & 37 \\
\hline & Green & 3 & 525 to 605 & & \\
\hline & Red & 4 & 633 to 690 & & \\
\hline & NIR-1 & 5 & 775 to 805 & & \\
\hline & NIR-2 & 6 & 845 to 890 & & \\
\hline & SWIR-1 & 7 & 1200 to 1300 & & \\
\hline & & 8 & 1550 to 1750 & & \\
\hline & & 9 & 2080 to 2350 & & \\
\hline Hyperion & $\begin{array}{l}\text { VNIR } \\
\text { SWIR }\end{array}$ & $\begin{array}{c}1 \text { to } 70 \\
71 \text { to } 242\end{array}$ & $\begin{array}{l}355 \text { to } 1057 \\
851 \text { to } 2577\end{array}$ & 30 & 7.7 \\
\hline
\end{tabular}




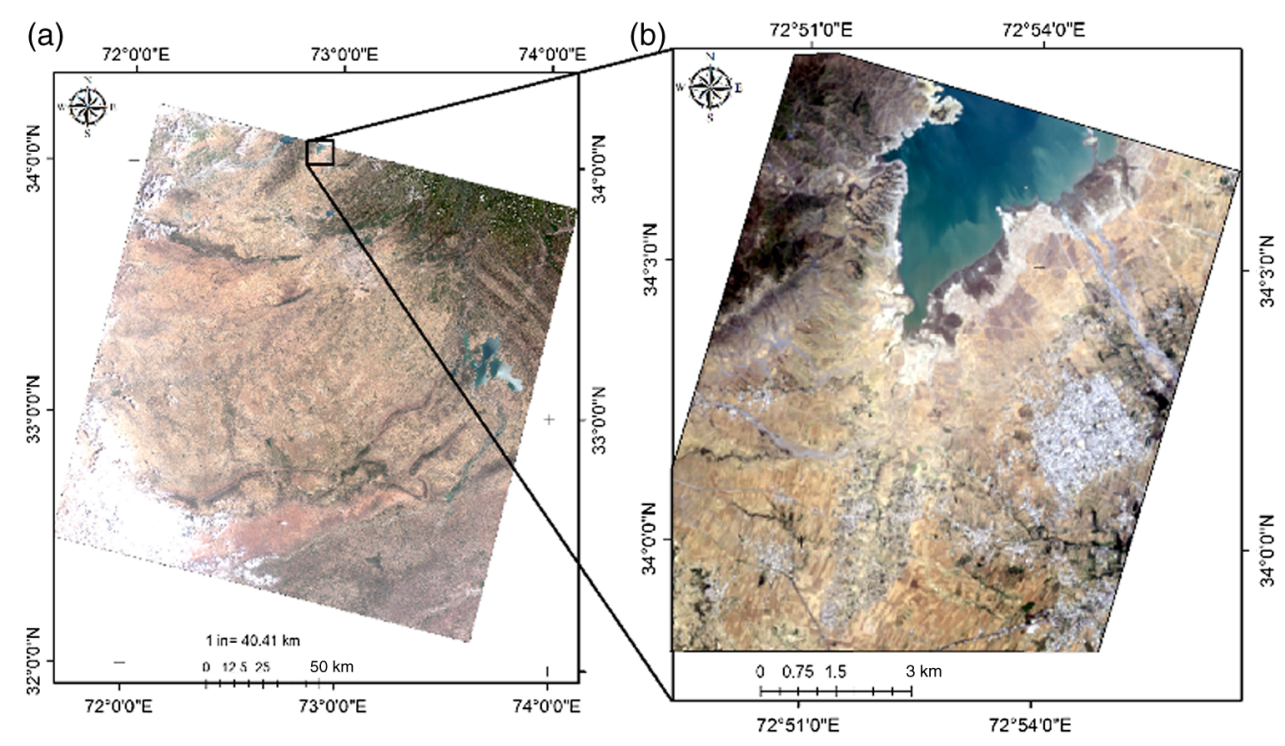

Fig. 2 Landsat-8 OLI: (a) orthoimage and (b) study area true color $\mathrm{R}=4=0.6554 \mu \mathrm{m}$, $\mathrm{G}=3=0.561 \mu \mathrm{m}, \mathrm{B}=1=0.443 \mu \mathrm{m}$.

172 bands in the short-wave infrared (SWIR; 851 to 2577), with a ground resolution of $30 \mathrm{~m}$ and a swatch width of $7.7 \mathrm{~km} .{ }^{39}$ OLI panchromatic and cirrus cloud bands, ALI panchromatic bands, and Hyperion bad bands were not included in this study.

Landsat-8 OLI data level 1T (terrain corrected) LC81500372015167LGN00_L1T (path/row 150/37) of the study area was acquired on June 16, 2015, and had a scene center latitude and longitude of 33.266 and 72.872, respectively (Fig. 2). For ALI and Hyperion, nearly coincident orthoimagery was acquired. ALI data level 1T (terrain corrected) 1500362005292_100011_L1T (path/row 150/36) was acquired on October 19, 2005, with a scene center latitude and longitude of 33.99 and 72.90, respectively (Fig. 3). Hyperion data level 1T (terrain corrected) EO11500372005285110KF_L1T (path/row 150/37) was acquired on October 12, 2005, with

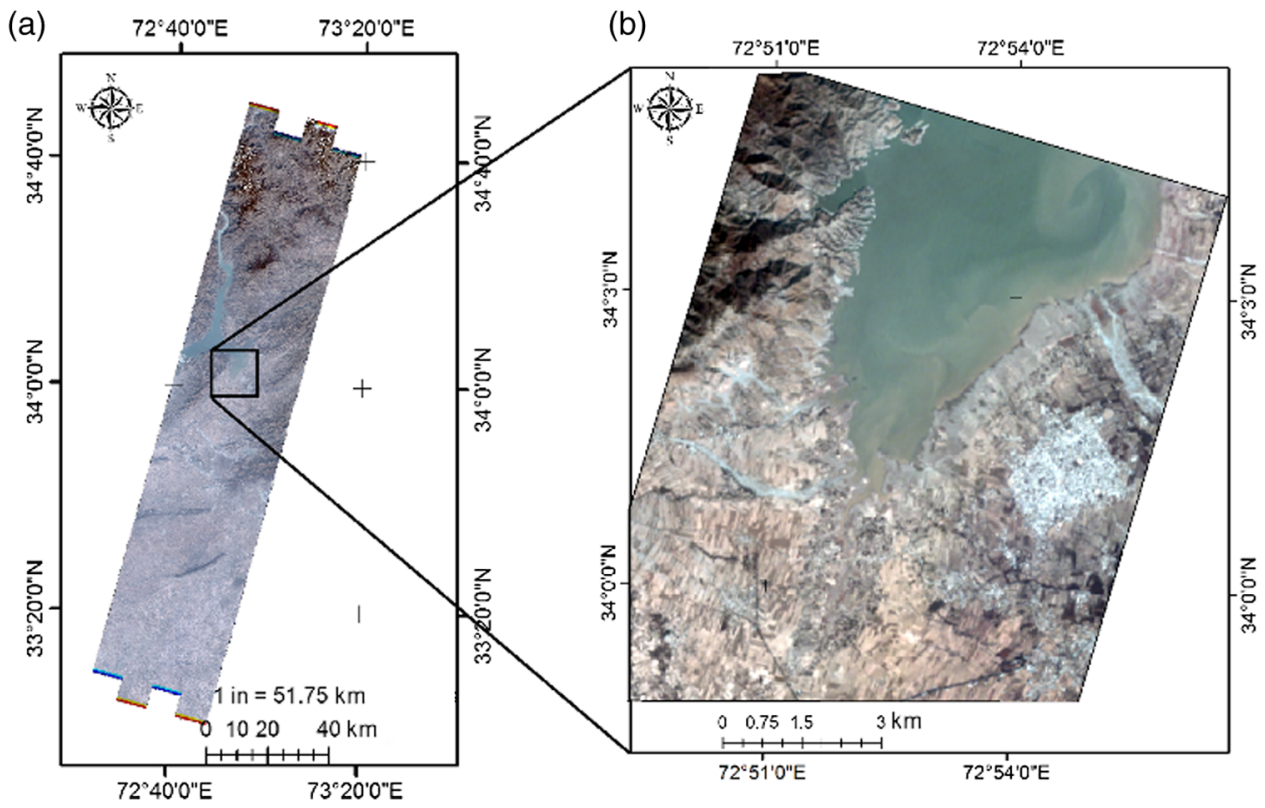

Fig. 3 ALI: (a) orthoimage and (b) study area true color $\mathrm{R}=4=0.660 \mu \mathrm{m}, \mathrm{G}=3=0.567 \mu \mathrm{m}$, $\mathrm{B}=1=0.441 \mu \mathrm{m}$. 
Pervez et al.: Satellite-based land use mapping: comparative analysis of Landsat-8...

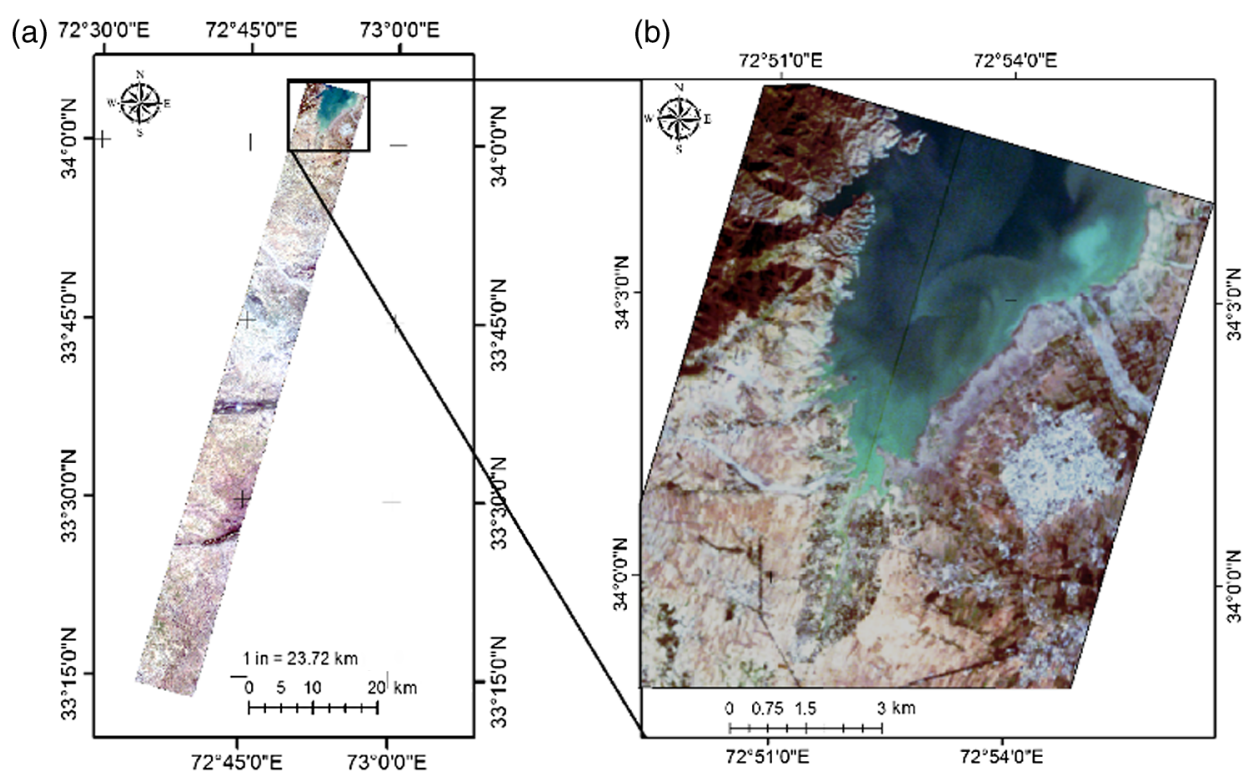

Fig. 4 Hyperion hyperspectral: (a) orthoimage and (b) study area true color $\mathrm{R}=29=0.641 \mu \mathrm{m}$, $\mathrm{G}=20=0.549 \mu \mathrm{m}, \mathrm{B}=11=0.458 \mu \mathrm{m}$.

a scene center latitude and longitude of 33.69 and 72.76, respectively, and in the Geo TIFF format (Fig. 4). In this study, the image map projection was Universal Transverse Mercator Zone 43N from the World Geodetic System 84 datum. In addition, nearly coincident imagery from OrbView-3 data 3V060702P0001269551A520000100292M_001609079_1GST was acquired on July 2, 2006, and was georeferenced (Fig. 5).

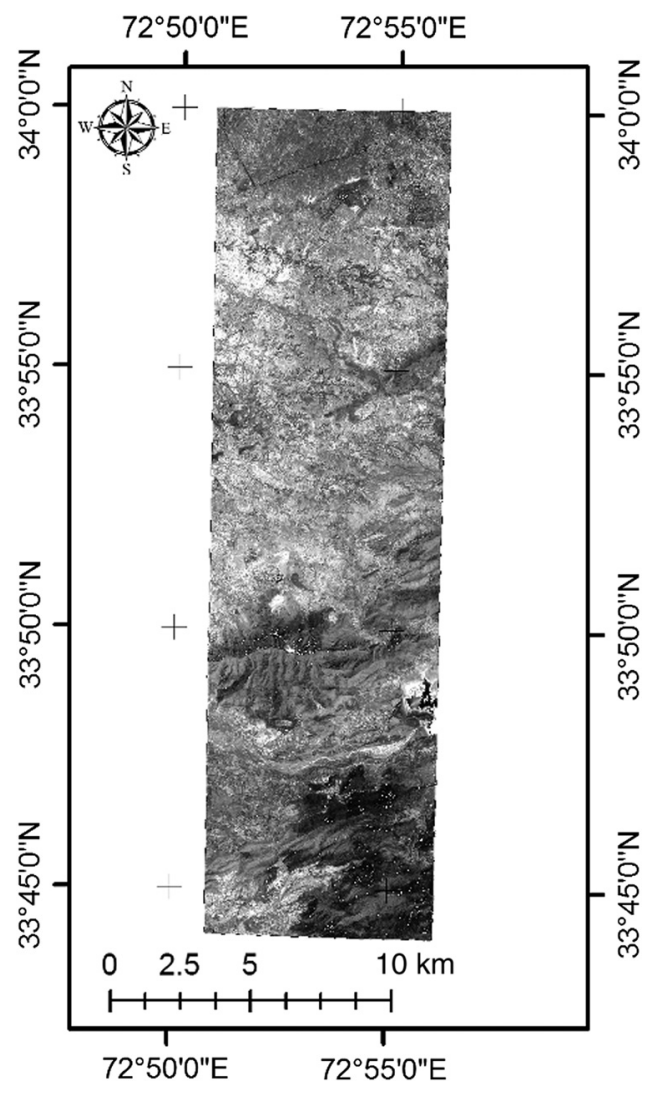

Fig. 5 OrbView-3 orthoimage. 


\section{Data Preprocessing}

\subsection{Digital Number to Radiance Conversion}

OLI, ALI, and Hyperion data were converted from digital number (DN) to radiance. Images were transformed into ENVI format files within the ENVI image-processing environment. These files contained information on wavelengths, bands, the transformation of DN to radiance/reflectance, and atmospheric corrections.

Equation (1) was used to convert DN values to spectral radiance using the spectral radiance scaling factor in the metadata file of OLI. ${ }^{40}$

$$
L_{\lambda}=M_{L} * Q_{\mathrm{cal}}+A_{L},
$$

where $L_{\lambda}$ is the radiance $\left(\mathrm{W} / \mathrm{m}^{2} \cdot \mathrm{sr} \cdot \mu \mathrm{m}\right), M_{L}$ is the multiplicative scaling factor for each band, $Q_{\text {cal }}$ is the pixel value in DN for level 1 , and $A_{L}$ is the additive scaling factor for each band.

Hyperion data preprocessing used the Hyperion tool.sav toolkit. EO1-Hyperion images contain hundreds of continuous spectral bands, each pixel of which stores energy as a 16-bit signed integer DN. Images with DN values were converted into absolute radiance values by dividing each band of VNIR (1 to 70) and SWIR (71 to 242) by its scale factor (i.e., 40 and 80, respectively). ${ }^{41}$ The image was subsequently saved in the ENVI standard format and converted to the bit in line data format.

\subsection{Radiance to Reflectance Conversion}

The FLAASH model was applied for atmospheric correction of OLI and ALI data in ENVI, and to convert radiance values into the top of atmospheric correction (TOA). FLAASH provides fast computational speed with ancillary data information of the scene and is used to improve results and consistency in further processing steps. A single scale factor value (1000) for all bands was used to convert the input radiance image $\left[\mathrm{W} /\left(\mathrm{m}^{2} \cdot \mu \mathrm{m} \cdot \mathrm{sr}\right) * 100\right]$ into standard FLAASH input radiance units of $\mu \mathrm{W} /\left(\mathrm{cm}^{2} \cdot \mathrm{nm} \cdot \mathrm{sr}\right)$. Reflectance values were multiplied by 10,000 in FLAASH images so that the resulting value was between 0 and 1 .

Equation (2) was used to convert DN values directly to TOA reflectance.

$$
\rho_{\lambda}^{\prime}=M \rho * Q_{\mathrm{cal}}+A_{\rho},
$$

where $\rho_{\lambda}$ is the spectral reflectance (unitless) without correction of solar angle, $M \rho$ is the multiplicative scaling factor for each band, $Q_{\text {cal }}$ is the pixel value in DN (level 1), and $A_{\rho}$ is the additive scaling factor for each band.

Equation (3) was used to convert TOA reflectance with solar angle.

$$
\rho_{\lambda}=\rho_{\lambda}^{\prime} \cdot \sin (\theta)
$$

where $\rho_{\lambda}$ is the TOA reflectance (unitless) and $\theta$ is the solar elevation angle.

Equation (4) was used on individual bands of the EO1-Hyperion hyperspectral image to convert radiance into reflectance, which was then stored for further processing steps. ${ }^{42}$

$$
\frac{\pi L_{\lambda} d^{2}}{\cos \theta_{s} \cdot \mathrm{ESUN}_{\lambda}},
$$

where $L_{\lambda}$ is the spectral radiance (at the sensor aperture), $d$ is the distance from the Earth to the Sun (astronomical units), $\mathrm{ESUN}_{\lambda}$ is the mean solar exo-atmospheric irradiance, and $\theta_{s}$ is the solar zenith angle (deg).

\subsection{Band Selection of Hyperion Hyperspectral Image}

Raw Hyperion orthoimagery contains 242 bands, of which 44 noncalibrated bands with zero values set during preprocessing of level 1B were removed (i.e., bands 1 to 7, 58 to 76, and 225 to 242). The remaining bands included low signal-to-noise value bands 77 and $78 ;^{43}$ 
water absorption bands 120 to 132,165 to 182,185 to 187 , and 221 to $224 ; ;^{23}$ and vertical stripping bands 8 to 9,56 to 57,79 to 82,97 to 99,133 to 134,152 to $153,188,213$ to 216 , and 219 to 220. After preprocessing, 136 calibrated bands were available for further analysis via QUAC (Table 3). No further processing was required, as the imagery had a processing level of L1_T.

\subsection{Quick Atmospheric Correction Applied to Hyperion Hyperspectral Imagery}

A scene-based approach for the atmospheric correction of hyperspectral imagery in VNIRSWIR was applied using the QUAC model. QUAC provides comparatively fast computational speed and has the advantage of using atmospheric compensation factors, without ancillary information, directly from the information contained within the image scene. QUAC achieves better retrievals of reflectance spectra in the absence of proper wavelength/radiometric calibration. For the atmospheric correction of Hyperion hyperspectral imagery, QUAC was applied in ENVI in order to improve the results and consistency in further processing steps. To compensate for atmospheric correction in water bodies, different approaches of QUAC and FLAASH have been used for multispectral and hyperspectral imagery. ${ }^{44-51}$ QUAC (for Hyperion) and FLAASH (for OLI and ALI) approaches were used for atmospheric correction.

\section{Results and Discussion}

\subsection{Principal Component Analysis of Hyperion Orthoimage}

PCA was applied to the 136 calibrated bands of the Hyperion orthoimage for the purposes of dimension reduction and further mapping applications.

The first 15 principal components (PCs; Table 4) accounted for $>99.9 \%$ of the information contained in the 136 bands, where the first PC was $94.14 \%$, the second PC was $4.8 \%$, and the third PC was $0.86 \%$; therefore, the dimensionality of the data was approximately 3 .

The PC1 band was highly uncorrelated, containing the maximum amount of data variance. Band PC2 contained the second-highest data variance, and PC 3 contained the third-largest data variance, but were also uncorrelated. PCs 4 to 15 were noisy and included little data variance. Being highly uncorrelated, bands PC1, PC2, and PC3 (containing 99.8\% of the data variance) were suitable for producing more colorful composite images than those available via spectral color-composite (Fig. 6).

\subsection{Spectral Profiles of Different Classes in Operational Land Imager, Advanced Land Imager, and Hyperion Orthoimages}

Distinct spectral profiling was possible for all classes (i.e., water, built-up area, mixed forest, shrub, and bare soil) within the OLI, ALI, and Hyperion orthoimagery (Fig. 7), which was

Table 3 Selected calibrated bands and wavelengths for the hyperspectral Hyperion orthoimage.

\begin{tabular}{lcc}
\hline \hline Channels & Wavelengths $(\mathrm{nm})$ & No. of bands \\
\hline 10 to 55 & 447.2 to 905.1 & 46 \\
83 to 96 & 972.9 to 1104.2 & 14 \\
100 to 119 & 1144.5 to 1336.2 & 10 \\
135 to 151 & 1497.7 to 1659.1 & 11 \\
154 to 164 & 1689.3 to 1790.2 & 2 \\
183 to 184 & 1981.8 to 1991.2 & 24 \\
189 to 212 & 2042.5 to 2274.4 & 2 \\
217 to 218 & 2324.9 to 2335.0 & 2 \\
\hline \hline
\end{tabular}


Pervez et al.: Satellite-based land use mapping: comparative analysis of Landsat-8...

Table 4 Eigenvalues, percentage variability, and cumulative percentage of the first 15 Hyperion orthoimage PCs.

\begin{tabular}{lccc}
\hline \hline PC & Eigenvalue & Percentage variability & Cumulative percentage \\
\hline 1 & 129.3851 & 94.14 & 94.14 \\
2 & 5.1670 & 4.8 & 98.94 \\
3 & 1.1703 & 0.86 & 99.80 \\
4 & 0.0475 & 0.03 & 99.83 \\
5 & 0.0336 & 0.03 & 99.86 \\
6 & 0.0276 & 0.02 & 99.88 \\
7 & 0.0182 & 0.01 & 99.89 \\
8 & 0.0133 & 0.01 & 99.90 \\
9 & 0.0110 & 0.01 & 99.91 \\
10 & 0.0094 & 0.00 & 99.91 \\
11 & 0.0091 & 0.01 & 99.92 \\
12 & 0.0071 & 0.01 & 99.93 \\
13 & 0.0063 & 0.00 & 99.93 \\
14 & 0.0057 & 0.00 & 99.93 \\
15 & 0.0051 & 0.01 & 99.94 \\
\hline \hline
\end{tabular}

beneficial for image classification. Spectral profiling of water (Fig. 7) is unique in IR regions, as it absorbs all the incident energy and causes a gradual decrease in reflectance with the increase in wavelength. However, in the visible part of the spectrum, water reflects only a small amount of radiation and has increased reflectance. Shrub and mixed forest reflectance in the IR region increases more rapidly than in the visible region. However, in the blue and red parts of the visible

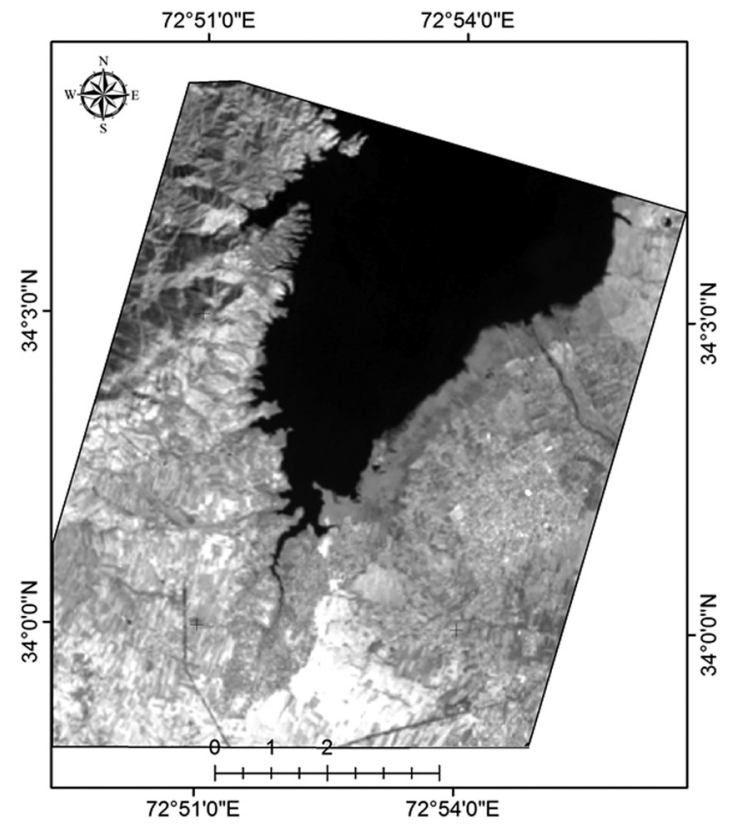

Fig. 6 Image of PC1. 
Pervez et al.: Satellite-based land use mapping: comparative analysis of Landsat-8...
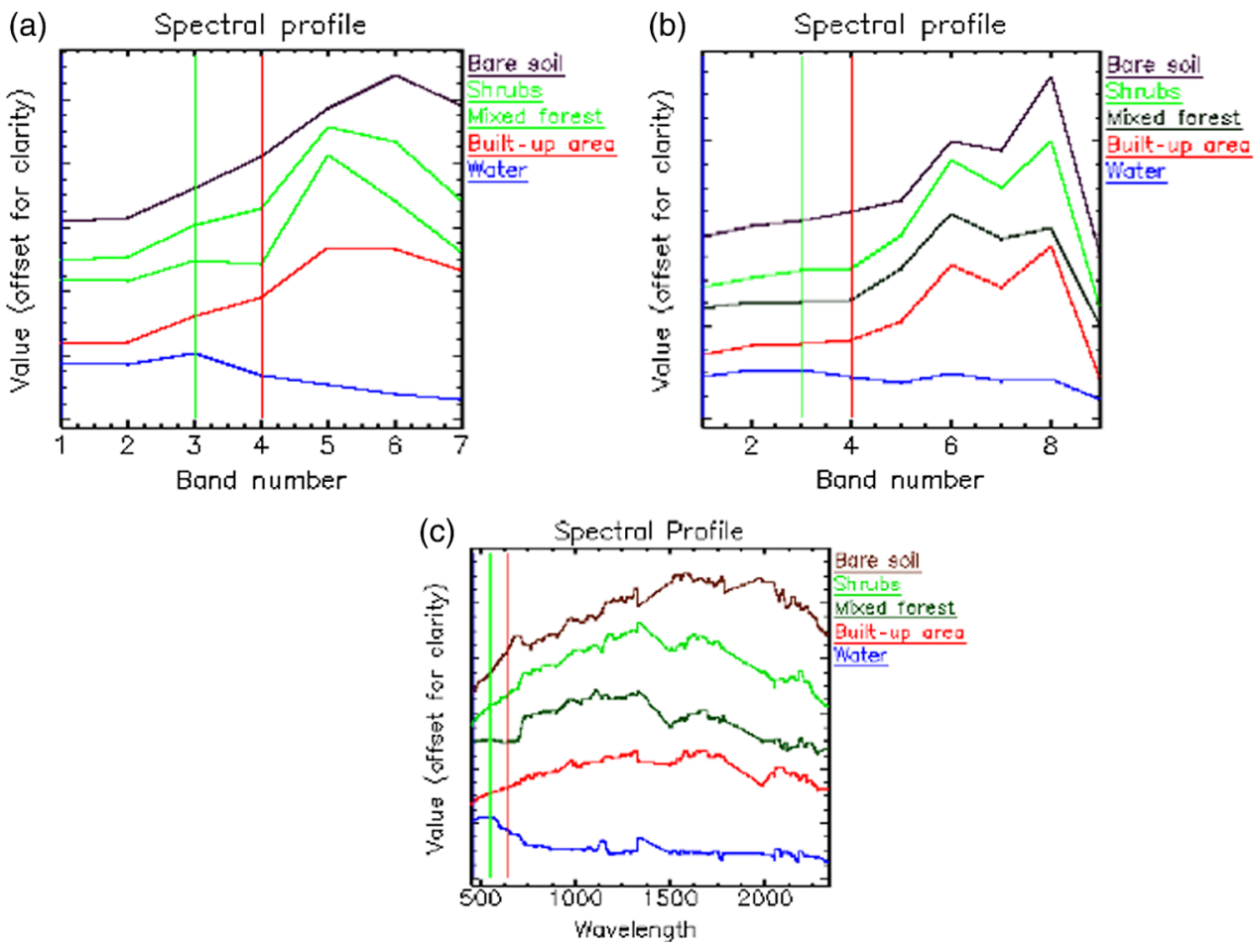

Fig. 7 Spectral profiles of different classes from the orthoimages of (a) Landsat-8 OLI, (b) ALI, and (c) Hyperion.

spectrum (chlorophyll absorption bands), radiation is absorbed and reflectance is reduced. In the IR region, mixed forest shows greater reflectance than shrub. Spectral profiling of built-up areas generally increases with increasing wavelength in the visible and IR bands. Spectral profiling of soil is unique, as it increases with the increase in wavelength. However, the presence of moisture decreases its reflectance at a particular region.

\subsection{Design of Support Vector Machines}

Linear SVM is the simplest approach for separating classes. Training data with $n$ numbers of samples, represented by $x_{i}$, and its corresponding classes, can be expressed as $y_{i}, i=1,2, \ldots, n$, where $x \in R^{N}$ in an $N$-dimensional space and $y \in\{-1,+1\}$ is the class label. The discriminate function in the two-dimensional space can be expressed as $f(X)=\mathbf{w} \cdot x+c$, where $\mathbf{w}$ is a vector and $c$ is a scalar, $\mathbf{w}$ determines the orientation of the discriminating plane, and $c$ determines the offset of the discriminating plane. If $\mathbf{w} \cdot x+c>0, x_{i}$ belongs to the first class, and if $\mathbf{w} \cdot x+c<0, x_{i}$ belongs to the second class. Assuming all samples in the training sets satisfy the situation $|g(x)| \geq 1$, classification interval $2 /\|\mathbf{w}\|$, $\|\mathbf{w}\|$, or $\|\mathbf{w}\|^{2}$ will be the smallest. Equation (5) shows the optimal function.

$$
\operatorname{Min}_{w}=1 / 2\|w\|^{2}=1 / 2(\mathbf{w} \cdot \mathbf{w})
$$

It should satisfy Eq. (6) to maximize the classification margin and classify all training samples to be linearly separable. This results in optimal hyperplane $S$.

$$
y_{i}(\mathbf{w} \cdot x+c)-1 \geq 0, i=1,2, \ldots n
$$

Training samples in hyperplanes $S 1$ and $S 2$ are the samples that satisfy Eq. (7) and are the support vectors. Equation (7) was used to define the space by the set of functions 


$$
f_{\mathbf{w}, b}=\operatorname{ign}(\mathbf{w} \cdot x+c) .
$$

Using positive Lagrangian multipliers $\alpha_{i}, i=1,2, \ldots k$, the solution to the problem of $\|\mathbf{w}\|^{2}$ was obtained using two steps: (1) optimization techniques of standard quadratic programming and (2) transformation to a dual-space representation.

Equation (8) requires that $L_{(\mathbf{w}, c, \alpha)}$ be minimized with respect to $\mathbf{w}$ and $c$, and maximized with respect to $\alpha_{i} \geq 0$, while Eq. (9) shows the decision rule for a two-class problem.

$$
\begin{gathered}
L_{(\mathbf{w}, c, \alpha)}=1 / 2\|\mathbf{w}\|^{2}-\sum_{i=1}^{k} \alpha_{i} y_{i}\left(\mathbf{w} \cdot x_{i}+c\right)+\sum_{i=1}^{k} \alpha_{i}, \\
f(x)=\operatorname{sign}\left[\sum_{i=1}^{k} \alpha_{i} y_{i}\left(x \cdot x_{i}\right)+c\right] .
\end{gathered}
$$

To improve classification accuracy and minimize misclassification errors, the relaxation factor $\xi_{i} \geq 0(i=1,2, \ldots, n)$ was introduced, which is controlled by a positive constant $C$ such that $\infty<C<0$. Therefore, for nonseparable data, Eq. (8) becomes

$$
L_{(\mathbf{w}, c, \alpha, \mu)}=1 / 2\|w\|^{2}+C \sum_{i=1} \xi_{i}-\sum_{i=1} \alpha_{i}\left[y_{i}\left(\mathbf{w} \cdot x_{i}+c\right)-1+\xi_{i}\right]-\sum_{i=1} \mu_{i} \xi_{i},
$$

where the Lagrange multiplier $\mu_{i}$ is used to enforce $q$ positive value of $\xi_{i}$. The solution to Eq. (10) required minimizing $\mathbf{w}, \xi$, and $c$, and maximizing $\alpha_{i} \geq 0$ and $\mu_{i} \geq 0$.

For a nonlinear decision surface, $x \in R^{N}$ was mapped via a nonlinear vector function $\phi$ by replacing $x_{i}$ and $x_{j}$ with $\phi\left(x_{i}\right)$ and $\phi\left(x_{j}\right)$; thus, Eq. (9) became

$$
f(x)=\operatorname{sign}\left[\sum_{i=1}^{k} \alpha_{i} y_{i} \phi(x) \cdot \phi\left(x_{i}\right)+c\right] .
$$

Equation (11) requires the computation of scalar products $\phi(x)$ and $\phi(y)$, whose computation is difficult. ${ }^{12,13}$ Therefore, Eq. (12) was used to define a kernel function to be commutated instead of $\phi(x)$.

$$
K\left(x_{i}, x_{j}\right)=\phi\left(x_{i}\right) \cdot \phi\left(x_{j}\right)
$$

Equation (13) represents a nonlinear case for the dual optimization problem.

$$
\max L_{(\mathbf{w}, c, \alpha)}=\sum_{i=1}^{k} \alpha_{i}-1 / 2 \sum_{i=1}^{k} \sum_{j=1}^{k} \alpha_{i} \alpha_{j} y_{i} y_{j} K\left(x_{i} \cdot x_{j}\right),
$$

subject to the constraints

$$
\sum_{i=1}^{k} \alpha_{i} y_{i}=0 \quad \text { and } \quad C \geq \alpha_{i} \geq 0
$$

\subsection{Operational Land Imager Classification}

SVM and SAM pixel-based supervised classifiers were established and executed on OLI orthoimagery. In the first step, classes (i.e., water, built-up area, mixed forest, shrub, and bare soil) were identified and formulated. In the second step, training samples for each class were collected from the orthoimage (i.e., 5 partitions of 355 samples for water, 2 partitions for 243 samples of built-up area, 2 partitions for 62 samples of mixed forest, 2 partitions for 47 samples of shrub, 6 partitions for 202 samples of bare soil). The selection of training samples was guided by survey maps, familiarity with the study area, selected field visits, and interpretation of photographic imagery, namely panchromatic black-and-white OrbView-3 (1 m resolution), ALI panchromatic imagery (10 m spatial resolution), and Google Earth software. The training sites were selected at 
locations of consistent and prominent land cover. In the third step, the SVM and SAM classifiers were established and executed within the ENVI image-processing environment using the training samples collected in the previous steps.

\subsubsection{Support vector machine classification}

SVM classification was established and executed for OLI orthoimagery in ENVI using multiclass classification with the same number and partition of training samples [e.g., Fig. 8(a)]. The parameter gamma $(\gamma)$ was calculated as the inverse of the number of spectral bands of the OLI orthoimage and was assigned a value of 0.143 . The penalty parameter was assigned its maximum value (i.e., 100), which forced all training pixels to be assigned to a certain class. The pyramid parameter was assigned a zero value so that the OLI orthoimage would be processed at full resolution. The classification probability threshold was assigned a zero value so that the entire pixel would be assigned to a specific class, leaving no unclassified pixels in the image. For the SVM classifier, the radial basis function (RBF) was selected as the kernel in order to achieve better results than using other kernels (e.g., linear, polynomial, and sigmoid). Equation (15) shows the RBF inner product function form.

$$
K(x, y)=\exp \left\{-\frac{|x-y|^{2}}{2 \sigma^{2}}\right\}
$$

where $x$ and $y$ are two samples represented as feature vectors in some input space, and $\sigma$ is variance.

\subsubsection{Spectral angle mapper classification}

The SAM classifier was also established and executed on the OLI orthoimage and implemented in ENVI with the same number and partition of training samples [e.g., Fig. 8(b)]. The maximum angle (radians) was set to 0.3 .

\subsection{Advanced Land Imager Classification}

SVM and SAM pixel-based supervised classifiers were established and executed on the ALI orthoimage. Classification of ALI orthoimagery followed the same steps described in Sec. 4.4.
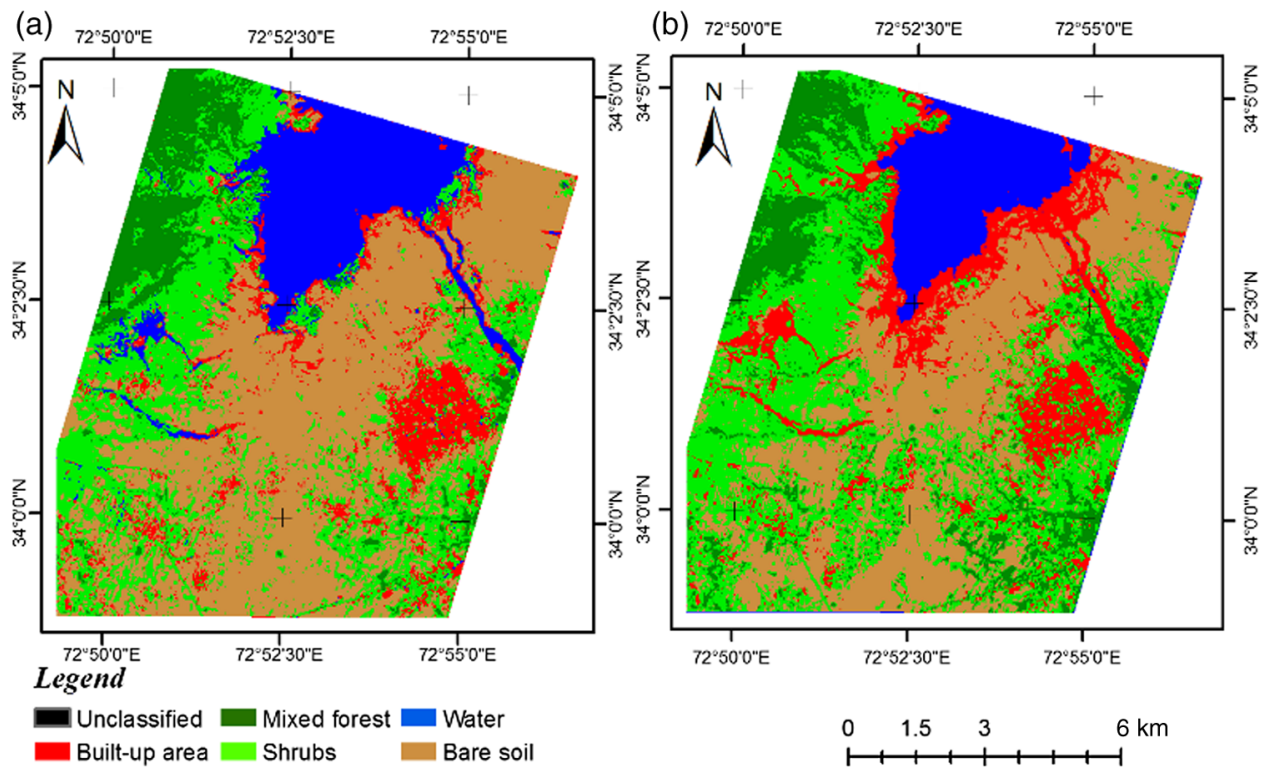

Fig. 8 Landsat-8 OLI orthoimagery classified by (a) the SVM model and (b) the SAM classifier. 


\subsubsection{Support vector machine classification}

The SVM classifier was established and executed on ALI orthoimagery and implemented in ENVI using multiclass classification with the same number and partition of training samples [e.g., Fig. 9(a)]. The parameter gamma $(\gamma)$ was calculated as the inverse of the number of spectral bands of ALI orthoimagery and was assigned a value of 0.111 . The same values and kernel as previously described (Sec. 4.4.1) were used for the penalty parameter, pyramid parameter, classification probability threshold, and kernel as radial basis function (RBF).

\subsubsection{Spectral angle mapper classification}

The SAM classifier was also established and executed on ALI orthoimage and implemented in ENVI with the same number and partition of training samples [e.g., Fig. 9(b)]. The maximum angle (radians) was assigned a value of 0.5 .

\subsection{Hyperion Hyperspectral Classification}

SVM and SAM pixel-based supervised classifiers were applied to the Hyperion orthoimage. Classification of Hyperion used the same steps as previously described (Sec. 4.4).

\subsubsection{Support vector machine classification}

The SVM classifier was established and executed on the Hyperion hyperspectral orthoimage and implemented in ENVI via multiclass classification with the same number and partition of training samples [e.g., Fig. 10(a)]. The parameter gamma $(\gamma)$ was calculated as the inverse of the number of spectral bands of ALI orthoimagery and was assigned a value of 0.007 . The same values described previously (Sec. 4.4.1) were used for the penalty parameter, pyramid parameter, classification probability threshold, and kernel as RBF.

\subsubsection{Spectral angle mapper classification}

The SAM classifier was also established and executed on the Hyperion orthoimage and implemented in ENVI with the same number and partition of training samples [e.g., Fig. 10(b)]. The maximum angle (radians) was set to 0.5 .

(a)

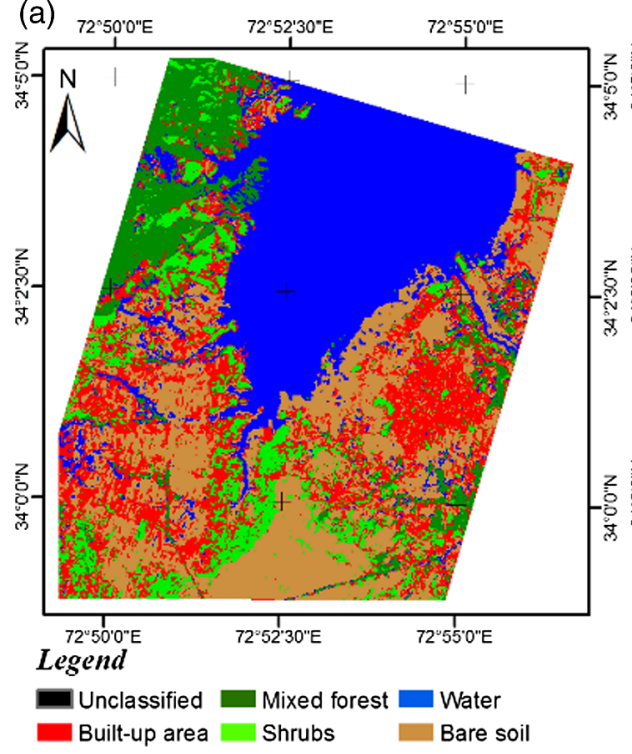

(b) $72^{\circ} 50^{\circ} 0^{\circ} \mathrm{E}$

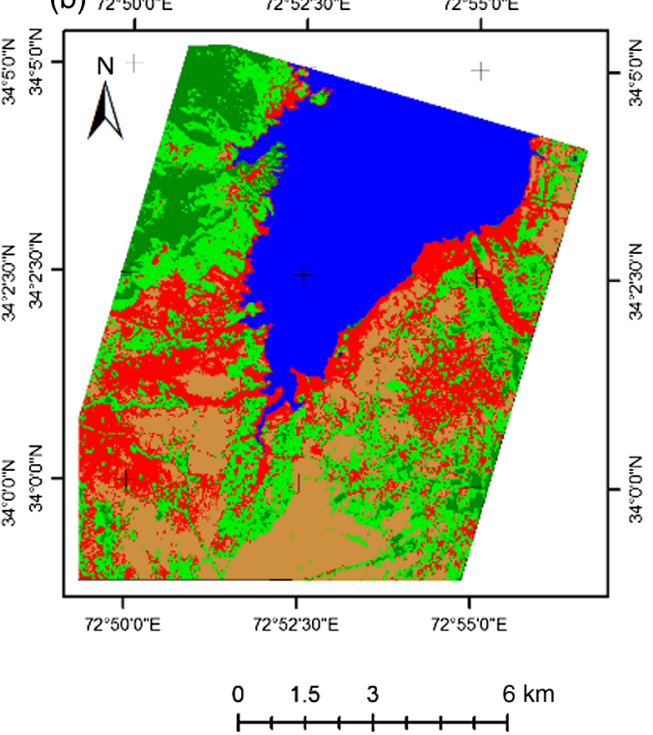

Fig. $9 \mathrm{ALI}$ orthoimagery classified by (a) the SVM model and (b) the SAM classifier. 
Pervez et al.: Satellite-based land use mapping: comparative analysis of Landsat-8...
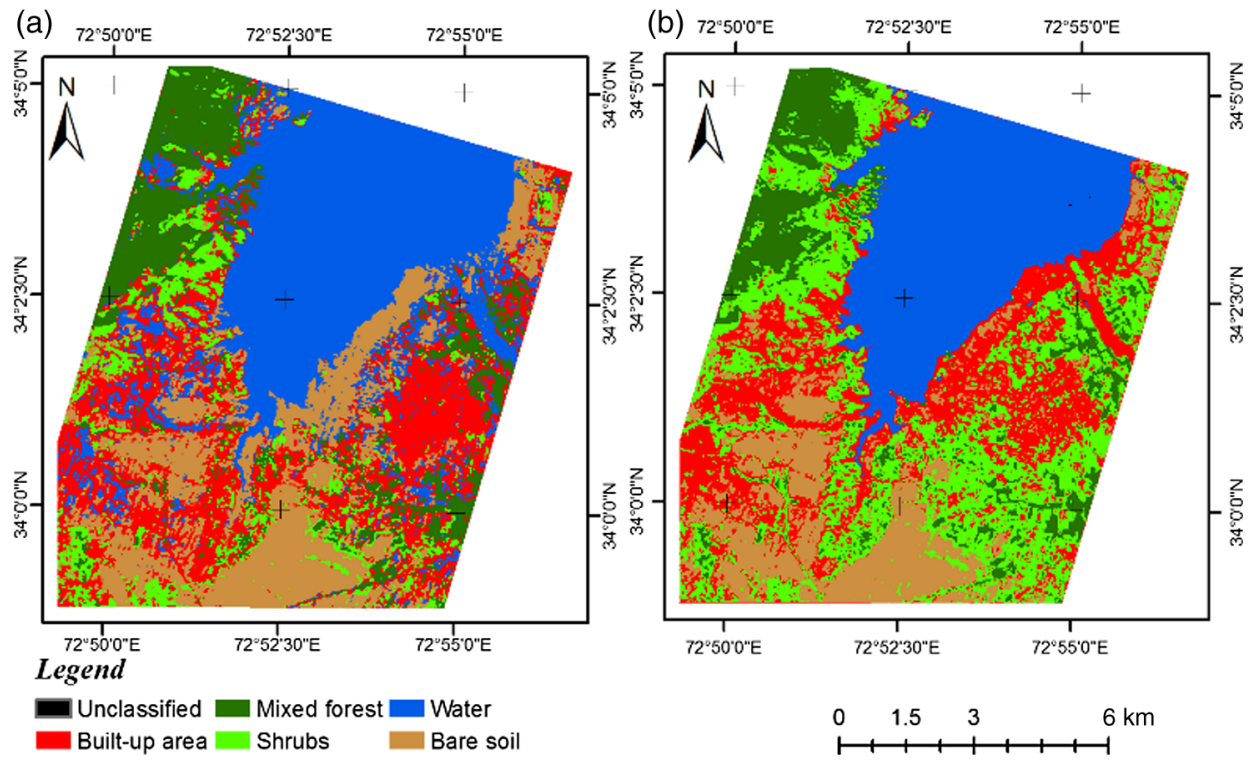

Fig. 10 Hyperion orthoimagery classified by (a) the SVM model and (b) the SAM classifier.

\subsection{Classification Accuracy}

Based on the confusion matrix, classification accuracy assessment was developed and implemented in ENVI using the SVM and SAM classification techniques on the OLI, ALI, and Hyperion orthoimages, thereby giving an overall accuracy and kappa coefficient. Classification accuracy was assessed using half of the samples as test points/ground truth and compared with training data sets for OLI, ALI, and Hyperion orthoimagery (Tables 5-10). Both classifiers achieved good results for spatial distribution and cover density of each class. Classification accuracy was used to select the most appropriate classifier for orthoimagery of the study area and the best study area orthoimage. The results showed that SVM was more accurate than SAM, both for overall accuracy and within individual classes.

For OLI orthoimagery, the overall accuracy and kappa coefficient were $92.52 \%$ and 0.8974 , respectively, for SVM (Table 5), and $85.59 \%$ and 0.8053 for SAM (Table 6). For ALI orthoimagery, the overall accuracy and kappa coefficient were $85.37 \%$ and 0.7986 , respectively, for SVM (Table 7), compared with $75.90 \%$ and 0.6724 for SAM (Table 8). For Hyperion hyperspectral orthoimagery, the overall accuracy was $98.57 \%$ and the kappa coefficient was 0.9802 using the SVM classifier (Table 9), compared with $79.32 \%$ and 0.7184 , respectively, when using SAM (Table 10).

Table 5 Landsat-8 OLI SVM model ground truth (\%). ${ }^{a}$

\begin{tabular}{lccccc}
\hline \hline \multicolumn{1}{c}{ Class } & Water & Built-up area & Mixed forest & Shrub & Bare soil \\
\hline Unclassified & 0.00 & 0.00 & 0.00 & 0.00 & 0.00 \\
Water & 90.14 & 0.82 & 0.00 & 0.00 & 0.00 \\
Built-up area & 6.76 & 89.71 & 0.00 & 0.00 & 0.00 \\
Mixed forest & 0.00 & 0.00 & 100 & 0.00 & 0.00 \\
Shrub & 0.28 & 7.00 & 0.00 & 93.62 & 2.48 \\
Bare soil & 2.82 & 2.47 & 0.00 & 6.38 & 97.52 \\
Total & 100.00 & 100.00 & 100.00 & 100.00 & 100.00 \\
\hline \hline
\end{tabular}

${ }^{\mathrm{a} O v e r a l l}$ accuracy $=92.52 \%$, Kappa coefficient $=0.8974$. 
Pervez et al.: Satellite-based land use mapping: comparative analysis of Landsat-8...

Table 6 Landsat-8 OLI SAM ground truth (\%). ${ }^{a}$

\begin{tabular}{lccccc}
\hline \hline \multicolumn{1}{c}{ Class } & Water & Built-up area & Mixed forest & Shrub & Bare soil \\
\hline Unclassified & 0.00 & 0.00 & 0.00 & 0.00 & 0.00 \\
Water & 78.59 & 0.00 & 0.00 & 0.00 & 0.00 \\
Built-up area & 19.15 & 86.42 & 0.00 & 4.26 & 0.50 \\
Mixed forest & 0.00 & 0.41 & 98.39 & 0.00 & 0.00 \\
Shrub & 1.41 & 12.76 & 1.61 & 89.36 & 7.43 \\
Bare soil & 0.85 & 0.41 & 0.00 & 6.38 & 92.08 \\
Total & 100.00 & 100.00 & 100.00 & 100.00 & 100.00 \\
\hline \hline
\end{tabular}

${ }^{\mathrm{a} O v e r a l l}$ accuracy $=85.59 \%$, Kappa coefficient $=0.8053$.

Table 7 ALI SVM model ground truth (\%). ${ }^{a}$

\begin{tabular}{lccccc}
\hline \hline \multicolumn{1}{c}{ Class } & Water & Built-up area & Mixed forest & Shrub & Bare soil \\
\hline Unclassified & 0.00 & 0.00 & 0.00 & 0.00 & 0.00 \\
Water & 81.69 & 0.00 & 0.00 & 0.00 & 0.00 \\
Built-up area & 2.25 & 88.48 & 0.00 & 17.02 & 0.50 \\
Mixed forest & 0.00 & 0.00 & 100.00 & 2.13 & 0.00 \\
Shrub & 0.00 & 3.29 & 0.00 & 80.85 & 0.00 \\
Bare soil & 16.06 & 8.23 & 0.00 & 0.00 & 84.65 \\
Total & 100.00 & 100.00 & 100.00 & 100.00 & 100.00 \\
\hline \hline
\end{tabular}

averall accuracy $=85.37 \%$, Kappa coefficient $=0.7986$.

Table 8 ALI SAM ground truth (\%). ${ }^{a}$

\begin{tabular}{lccccc}
\hline \hline \multicolumn{1}{c}{ Class } & Water & Built-up area & Mixed forest & Shrub & Bare soil \\
\hline Unclassified & 0.00 & 0.00 & 0.00 & 0.00 & 0.00 \\
Water & 78.31 & 0.00 & 0.00 & 0.00 & 0.00 \\
Built-up area & 16.34 & 76.95 & 0.00 & 2.13 & 41.09 \\
Mixed forest & 0.00 & 0.00 & 96.77 & 0.00 & 0.00 \\
Shrub & 0.00 & 13.99 & 3.23 & 97.87 & 0.00 \\
Bare soil & 5.35 & 9.05 & 0.00 & 0.00 & 58.91 \\
Total & 100.00 & 100.00 & 100.00 & 100.00 & 100.00 \\
\hline \hline
\end{tabular}

${ }^{\mathrm{a} O v e r a l l ~ a c c u r a c y}=75.91 \%$, Kappa coefficient $=0.6724$.

Hyperion maps with SVM classification (98.57\%) were considered reference maps and the validation source. On this basis, OLI and ALI both reasonably achieved land use/cover mapping.

SVM classification of OLI achieved higher accuracy $(92.52 \%)$ than did SVM and SAM classifiers with the ALI orthoimage. The greater classification accuracy of SVM was attributed to generalization of the optimal separating hyperplane with the least error among all hyperplanes. 
Pervez et al.: Satellite-based land use mapping: comparative analysis of Landsat-8...

Table 9 Hyperion SVM model ground truth (\%). ${ }^{a}$

\begin{tabular}{lccccc}
\hline \hline \multicolumn{1}{c}{ Class } & Water & Built-up area & Mixed forest & Shrub & Bare soil \\
\hline Unclassified & 0.00 & 0.00 & 0.00 & 0.00 & 0.00 \\
Water & 98.03 & 0.00 & 0.00 & 0.00 & 0.00 \\
Built-up area & 0.23 & 99.59 & 0.00 & 2.13 & 0.00 \\
Mixed forest & 0.00 & 0.00 & 95.16 & 2.13 & 0.00 \\
Shrub & 0.00 & 0.41 & 4.84 & 95.74 & 0.00 \\
Bare soil & 1.69 & 0.00 & 0.00 & 0.00 & 100.00 \\
Total & 100.00 & 100.00 & 100.00 & 100.00 & 100.00 \\
\hline \hline
\end{tabular}

${ }^{\mathrm{a} O v e r a l l}$ accuracy $=98.57 \%$, Kappa coefficient $=0.9802$.

Table 10 Hyperion SAM ground truth (\%). ${ }^{a}$

\begin{tabular}{lccccc}
\hline \hline \multicolumn{1}{c}{ Class } & Water & Built-up area & Mixed forest & Shrub & Bare soil \\
\hline Unclassified & 0.00 & 0.00 & 0.00 & 0.00 & 0.00 \\
Water & 78.59 & 0.00 & 0.00 & 0.00 & 0.00 \\
Built-up area & 18.03 & 79.84 & 0.00 & 2.13 & 28.22 \\
Mixed forest & 0.00 & 0.00 & 95.16 & 4.26 & 0.00 \\
Shrub & 0.00 & 10.70 & 4.84 & 93.62 & 0.00 \\
Bare soil & 3.38 & 9.47 & 0.00 & 0.00 & 71.78 \\
Total & 100.00 & 100.00 & 100.00 & 100.00 & 100.00 \\
\hline \hline
\end{tabular}

averall accuracy $=79.32 \%$, Kappa coefficient $=0.7184$.

With SAM classification, OLI achieved the highest accuracy (85.59\%). When using SAM classification, OLI orthoimagery was more accurate than ALI and Hyperion orthoimagery. SVM more effectively discriminated water, built-up area, mixed forest, shrub, and bare soil than did SAM.

Owing to its spectral band configuration and enhanced radiometric performance, when using the SVM classifier, OLI orthoimagery discriminated more effectively than did ALI for water (90.14 versus $81.69 \%)$, built-up area $(89.71 ; 88.48 \%)$, shrub $(93.62 ; 80.85 \%)$, and bare soil (97.52\%; 84.65\%).

Owing to its enhanced capabilities, when using the SAM classifier, OLI discriminated more effectively than did ALI for water (78.59 versus $78.31 \%)$, built-up area $(86.42 ; 76.95 \%)$, mixed forest $(98.39 ; 96.77 \%)$, and bare soil $(92.08 ; 58.91 \%)$. These results show that the new OLI technology allows for water classification more easily than did ALI and Hyperion orthoimagery. Similarly, more accurate bare soil mapping was achieved with OLI than with ALI orthoimagery using both the SVM and SAM classifiers. It was found that with the SAM classifier, some regions of bare soil were misclassified as shrub, and bare soil was misclassified as built-up area in OLI, ALI, and Hyperion orthoimagery. It was also found that with the passage of time, dam water reservoir capacity has fallen considerably owing to deposition and/or silting, with these changes clearer in OLI than in the ALI and Hyperion maps. Using the SVM classifier, some regions of built-up area surrounded by shrub were misclassified as shrub.

The results of this study are comparable to those of other remote sensing sensor studies. Otukei and Blaschke ${ }^{52}$ used decision trees, SVMs, and maximum likelihood classifiers, and reported that SVM achieved the highest accuracy. Nemmour and Chibani ${ }^{29}$ reported that 
SVM also outperformed artificial neural networks (ANN) when using Landsat Thematic Mapper imagery. Dixon and Candede ${ }^{18}$ found that an SVM classifier required less training time and fewer parameters than ANN. Pal and Mather ${ }^{36}$ found that SVM was superior to ANN when using multispectral Landsat Enhanced Thematic Mapper Plus imagery and the airborne hyperspectral sensor, for which SVM had an overall accuracy of more than $91 \%$. Karimi et al. ${ }^{53}$ found that SVM achieved $15 \%$ better accuracy and 0.114 higher kappa coefficient when using an airborne hyperspectral sensing system. Koetz et al. ${ }^{54}$ reported an overall accuracy of $69.15 \%$ and a kappa coefficient of 0.645 using hyperspectral and Lidar data. Licciardi et al. ${ }^{55}$ also reported SVM with higher overall accuracy due to its ability to achieve the ideal separating hyperplane by developing the least error among all hyperplanes. In these examples, hyperplanes were defined by kernel functions; however, the literature rarely includes guidance on the selection of a specific kernel. ${ }^{13,56,57}$

\subsection{Sources of Error}

Having the same sensor altitude for Landsat-8 OLI, ALI, and Hyperion had no apparent effect on viewing geometry and had a negligible effect on the mapping application. Atmospheric correction of OLI, ALI, and Hyperion improved consistency in the data and improved the accuracy of the mapping application. Thus, the geometric and radiometric errors that affect accuracy were minimized and/or removed to achieve more accurate maps.

\section{Summary and Conclusions}

The results of this study confirmed the potential utility of OLI, ALI, and Hyperion orthoimagery for analysis of the study area. Distinct spectral profiles were identified for all classes (i.e., water, built-up area, mixed forest, shrub, and bare soil) for each of the three sensors, which is highly beneficial for feature identification and classification of images. Accuracy was assessed via SVM and SAM classification techniques, which effectively selected the most appropriate classifier for the study area and the best study area orthoimagery.

OLI, ALI, and Hyperion data were preprocessed and atmospherically corrected using FLAASH and QUAC. The preprocessing of 242 bands of hyperspectral data effectively resulted in 136 calibrated bands. QUAC was applied to these calibrated bands for atmospheric correction, and PCA was used for dimensional reduction of the data. PCA revealed that $99.94 \%$ of the hyperspectral data were contained in the first 15 PCs. For Hyperion hyperspectral data, the first three PCs contained $99.8 \%$ of the information, which is highly beneficial for applying the most common classifiers; thus, the dimensionality of the hyperspectral data was considered to be three.

The SVM and SAM classifiers were developed and implemented for OLI, ALI, and Hyperion orthoimages, and all classes (i.e., water, built-up area, mixed forest, shrub, and bare soil) were effectively discriminated. OLI orthoimagery with SVM outperformed the SAM classifier (overall accuracy of $92.52 \%$ versus $85.59 \%$ ). Similarly, ALI orthoimagery with SVM outperformed the SAM classifier (overall accuracy of 85.36 versus $75.90 \%$ ). Hyperion orthoimagery was more accurate with SVM than with the SAM classifier (overall accuracy of 98.57 versus $79.32 \%$ ). Thus, SVM produced better results than SAM with OLI, ALI, and Hyperion orthoimagery. The Hyperion hyperspectral orthoimage with the SVM classifier produced higher overall accuracy $(98.57 \%)$ than the OLI $(92.52 \%)$ and ALI $(85.37 \%)$ orthoimages. Using the SVM classifier, OLI orthoimagery performed better than ALI, both for overall accuracy (92.52 versus $85.37 \%$ ) and individual classes. Using the SAM classifier, OLI outperformed both ALI and Hyperion in terms of overall accuracy $(85.59,79.32$, and $75.91 \%$, respectively) and in individual classes.

Using the SVM classifier, OLI orthoimagery discriminated water (90.14 versus $81.69 \%)$, built-up area ( 89.71 versus $88.48 \%$ ), shrub (93.62 versus $80.85 \%$ ), and bare soil (97.52 versus 84.65) more effectively than ALI. Using the SAM classifier, ALI orthoimagery discriminated water (78.59 versus $78.31 \%$ ), built-up area (86.42 versus $76.95 \%)$, mixed forest (98.39 versus 96.77\%), and bare soil (92.08 versus 58.91\%) more effectively than ALI. 
The results show the new OLI technology allows for easier and more accurate water classification than do ALI and Hyperion. When using the SAM classifier, some misclassifications of bare soil as shrub and bare soil as built-up area were found in OLI, ALI, and Hyperion orthoimagery. When using the SVM classifier, some built-up areas surrounded by shrub were misclassified as shrub.

Remote sensing is an important means of Earth observation. For example, the OLI data applied to water mapping clearly showed the reduction in dam water reservoir capacity owing to silt deposition. The results confirmed that the enhanced capabilities of OLI (e.g., enhanced radiometric conformity and spectral band configuration) allow it to outperform ALI in terms of classification accuracy, while Hyperion maps with SVM classification can be used as a validation source. In conclusion, the new OLI technology allows for more accurate mapping of land use/cover in the study area.

\section{Acknowledgments}

The authors thank Dr. Arshad Aziz, Dr. Faisal Amir, Dr. Attah Ullah Memon, Dr. Pervez Akhtar, Dr. Ijaz Hussain, Dr. Salman Atif, and Dr. Mohammad Salman of the National University of Sciences \& Technology; and Dr. Mohammad Ali Maud of the University of Engineering \& Technology of Pakistan. The authors are also grateful to the U.S. Geological Survey for their help and support. English language editing was performed by Editage.

\section{References}

1. B. L. Markham et al., "The Landsat data continuity mission Operational Land Imager (OLI) radiometric calibration," in IEEE Int. Geoscience and Remote Sensing Symp., pp. 22832286 (2010).

2. U.S. Geological Survey, Landsat Data Continuity Mission, U.S. Geological Survey, Washington, DC (2012).

3. A. D. Gerace, "Demonstrating Landsat's new potential to monitor coastal and inland water," $\mathrm{PhD}$ Dissertation, Department of Imaging Science, Rochester Institute of Technology, Rochester, New York (2010).

4. A. Gerace and J. Schott, "The increased potential of the Landsat data continuity mission to contribute to case 2 water quality studies," Proc. SPIE 7452, 74520U (2009).

5. N. Pehlevan and J. R. Schott, "Investigating the potential of the Operational Land Imager (OLI) for monitoring case II waters using a look-up-table approach," in Pecora 18: Forty Years of Earth Observation-Understanding a Changing World, Herndon, Virginia (2011).

6. S. N. Kloiber et al., "A procedure for regional lake water clarity assessment using Landsat multispectral data," Remote Sens. Environ. 82, 38-47 (2002).

7. M. Folkman et al., "EO-1/Hyperion hyperspectral imager design, development, characterization, and calibration," Proc. SPIE 4151, 40 (2001).

8. L. C. Sanders, J. R. Schott, and R. Raqueno, "A VNIR/SWIR atmospheric correction algorithm for hyperspectral imagery with adjacency effect," Remote Sens. Environ. 78, 252-263 (2001).

9. E. J. Hochberg, S. Andrefouet, and M. R. Tyler, "Sea surface correction of high surface resolution IKONOS images to improve bottom mapping in near shore environment," IEEE Trans. Geosci. Remote Sens. 41, 1724-1729 (2003).

10. D. Mishra et al., "Benthic habit mapping in tropical marine environments using Quick Bird multispectral data," Photogramm. Eng. Remote Sens. 72, 1037-1048 (2006).

11. S. Andrefouet et al., "Multi-site evaluation of IKONOS data for classification of tropical coral reef environments," Remote Sens. Environ. 88, 128-143 (2003).

12. M. Pal, "Ensemble of support vector machines from land cover classification," Int. J. Remote Sens. 26(5), 1007-1011 (2008).

13. Y. Kavzoglu and I. Colkesen, "A kernel function analysis for support vector machines for land cover classification," Int. J. Appl. Earth Obs. Geoinf. 11, 352-359 (2009). 
Pervez et al.: Satellite-based land use mapping: comparative analysis of Landsat-8...

14. A. Mathur and G. M. Foody, "Crop classification by support vector machine with intelligently selected training data for nonoperational application," Int. J. Remote Sens. 29(8), 2227-2240 (2008).

15. H. Hakvoort et al., "Towards airborne remote sensing of water quality in the Netherlandsvalidation and error analysis," ISPRS J. Photogramm. Remote Sens. 57, 171-183 (2002).

16. S. Thiemann and H. Kaufmann, "Lake water quality monitoring using hyperspectral airborne data-a semiempirical multispectral and multitemporal approach for the Mecklenburg Lake District, Germany," Remote Sens. Environ. 81, 228-237 (2002).

17. M. J. Canty, "Boosting a fast neural network for supervised land cover classification," Comput. Geosci. 35(6), 1280-1295 (2009).

18. B. Dixon and N. Candade, "Multispectral land use classification using neural networks and support vector machines, one or the other, or both?," Int. J. Remote Sens. 29(4), 1185-1206 (2008).

19. P. Barry, "EO-1/Hyperion science data user's guide, level 1_B," May 2001, http://www.eoc. csiro.au/hswww/oz_pi/docs/EO1HSDataUsersGuide.pdf (18 March 2016).

20. R. Beck, EO-1 User Guide-Version 2.3, Satellite Systems Branch, USGS Earth Resources Observation Systems Data Center, Cincinnati (2003).

21. B. W. Pengra, C. A. Johnston, and T. R. Loveland, "Mapping an invasive plant, Phragmites australis, in coastal wetlands using the EO-1 Hyperion hyperspectral sensor," Remote Sens. Environ. 108(1), 74-81 (2007).

22. D. D. Xu et al., "Exploring for natural gas using reflectance spectra of surface soils," $A d v$. Space Res. 41, 1800-1817 (2008).

23. R. Zhang and J. Ma, "Feature selection for hyperspectral data based on recursive support vector machines," Int. J. Remote Sens. 30(14), 3669-3677 (2009).

24. P. Du, K. Tan, and X. Xing, "Wavelet SVM in reproducing kernel Hilbert space for hyperspectral remote sensing image classification," Opt. Commun. 283, 4978-4984 (2010).

25. S. Pignatti et al., "Evaluating Hyperion capability for land cover mapping in a fragmented ecosystem: Pollino National Park, Italy," Remote Sens. Environ. 113, 622-634 (2009).

26. J. Wang et al., "Application of geographic image cognition approach in land type classification using Hyperion image: a case study in China," Int. J. Appl. Earth Obs. Geoinf. 12S, S212-S222 (2010).

27. S. J. Walsh et al., "Quick Bird and Hyperion data analysis of an invasive plant species in the Galapagos Islands of Ecuador: implications for control and land use management," Remote Sens. Environ. 112, 1927-1941 (2008).

28. C. Huang, L. S. Davis, and G. Townshend Jr., "An assessment of support vector machines for land cover classification," Int. J. Remote Sens. 23, 725-749 (2002).

29. H. Nemmour and Y. Chibani, "Multiple support vector machines for land cover change detection: an application for mapping urban extension," ISPRS J. Photogramm. 61, 125-133 (2006).

30. M. L. Clark, D. A. Roberts, and D. B. Clark, "Hyperspectral discrimination of tropical rain forest tree species at leaf to crown scales," Remote Sens. Environ. 96, 375-398 (2005).

31. D. Vyas et al., "Evaluation of classifiers for processing Hyperion (EO-1) data of tropical vegetation," Int. J. Appl. Earth Obs. Geoinf. 13, 228-235 (2011).

32. M. Dalponte et al., "The role of spectral resolution and classifier complexity in the hyperspectral images of forest areas," Remote Sens. Environ. 113, 2345-2355 (2009).

33. A. Plaza et al., "Recent advances in techniques for hyperspectral image processing," Remote Sens. Environ. 113, S110-S122 (2009).

34. K. P. Soman, V. Ajay, and R. Loganathan, Machine Learning with SVM and Other Kernel Methods, Prentice-Hall, India (2009).

35. F. Melgani and L. Bruzzone, "Classification of hyperspectral remote sensing image with support vector machines," IEEE Trans. Geosci. Remote Sens. 42, 1778-1790 (2004).

36. M. Pal and P. M. Mather, "Some issues in the classification of DAIS hyperspectral data," Int. J. Remote Sens. 27, 2895-2916 (2006).

37. S. G. Ungar et al., "Overview of the Earth Observing One (EO-1) mission," IEEE Trans. Geosci. Remote Sens. 41, 1149-1159 (2003). 
38. D. Roy et al., "Landsat-8: science and product vision for terrestrial global change research," Remote Sens. Environ. 145, 154-172 (2014).

39. D. R. Hearn et al., "EO-1 Advanced Land Imager overview and spatial performance," IEEE Trans. Geosci. Remote Sens. 2, 897-899 (2001).

40. Landsat 8 (L8) Data Users Handbook, LSDS-1574 Version 1.0, Department of the Interior U.S. Geological Survey, EROS Sioux Falls, South Dakota (2015).

41. P. S. Thenkabail et al., "Accuracy assessments of hyperspectral waveband performance for vegetation analysis applications," Remote Sens. Environ. 91(3-4), 354-376 (2004).

42. P. S. Thenkabail et al., "Hyperion, IKONOS, ALI and ETM+ sensors in the study of African rainforests," Remote Sens. Environ. 90, 23-43 (2004).

43. B. Datt et al., "Preprocessing EO-1 Hyperion hyperspectral data support the application of agricultural indexes," IEEE Trans. Geosci. Remote Sens. 41, 1246-1259 (2003).

44. M. G. Allan et al., "Landsat remote sensing of chlorophyll a concentration in central North Island lakes of New Zealand," Int. J. Remote Sens. 32, 2037-2055 (2011).

45. Y. H. Ahn, P. Shanmugam, and J. E. Moon, "Retrieval of ocean colour from high resolution multi-spectral imagery for monitoring highly dynamic ocean features," Int. J. Remote Sens. 27, 367-392 (2006).

46. B. L. Markham et al., "Landsat-7 ETM+: 12 years on-orbit reflective-band radiometric performance," IEEE Trans. Geosci. Remote Sens. 50(5), 2056-2062 (2012).

47. D. A. Palandro et al., "Qualification of two decades of shallow-water coral reef habitat decline in the Florida Keys National Marine Sanctuary using Landsat data (19842002)," Remote Sens. Environ. 112, 3388-3399 (2008).

48. V. E. Brando and A. G. Dekker, "Satellite hyperspectral remote sensing for estimating estuarine and coastal water quality," IEEE Trans. Geosci. Remote Sens. 41, 1378-1387 (2003).

49. C. D. Mobley and L. K. Sundman, Hydrolight 5, Ecolight User Guide, Sequoia Scientific Inc., Bellevue, Washington (2008).

50. Z. Lee et al., "Removal of surface reflected light for the measurement of remote-sensing reflectance from an above-surface platform," Opt. Express 18, 26313-26324 (2010).

51. K. G. Ruddick, F. Ovidio, and M. Rijkeboer, "Atmospheric correction of SeaWiFS imagery for turbid coastal and inland waters," Appl. Opt. 39, 897-912 (2000).

52. J. R. Otukei and T. Blaschke, "Land cover change assessment using decision trees, support vector machines and maximum likelihood classification algorithms," Int. J. Appl. Earth Obs. Geoinf. 12(Suppl. 1), S27-S31 (2010).

53. Y. Karimi et al., "Application of support vector machine technology for weed and nitrogen stress detection in corn," Comput. Electron. Agric. 51, 99-109 (2006).

54. B. Koetz et al., "Multi source land cover classification for forest fire management based on imagine spectrometry and Lidar data," Forest Ecol. Manage. 256(3), 263-271 (2008).

55. G. Licciardi et al., "Decision fusion for classification of hyperspectral data: outcome of 2008 GRS-S Data Fusion Contest," IEEE Trans. Geosci. Remote Sens. 47(11), 38573865 (2009).

56. H. Carrao, P. Goncalves, and M. Caetano, "Contribution of multispectral and multi temporal information from MODIS images to land cover classification," Remote Sens. Environ. 112, 986-997 (2008).

57. S. Li and C. W. Liu, "A class possibility based kernel to increase classification accuracy for small data sets using support vector machines," Expert Syst. Appl. 37, 3104-3110 (2010).

Wasim Pervez is a PhD scholar and previous assistant professor at National University of Science \& Technology (NUST), Pakistan. He received his BSc in 1996 and his MSc in 2004 in electrical engineering from NUST and University of Engineering \& Technology (UET), Pakistan, respectively. He presented a research paper at the International Conference of Photogrammetric Image Analysis (Germany) in March 2015. His current research interests include remote sensing, GIS, image processing, feature extraction, and pattern recognition. 
Vali Uddin is a professor at Hamdard University, Pakistan. He received his BSc in 1989 and his MSc in 2002 in electronics and electrical engineering from NED University, Pakistan, and Boston University, respectively. He earned his $\mathrm{PhD}$ in electrical engineering from Boston University in 2000. He is the author/coauthor of more than 40 articles. His current research interests include image processing, signal processing, and control systems. He is a member of IEEE.

Shoab Ahmad Khan is a professor and head of department at NUST University, Pakistan. He received his MSc in 1992 and his PhD in 1995 in computer engineering from Georgia Tech. He has authored more than 260 international publications, including a book titled Digital Design (John Wiley \& Sons). He is the holder of five U.S. patents and many national awards. His current research interests include image processing, signal processing, and remote sensing.

Junaid Aziz Khan is a lecturer at NUST. He received his BSc in 2007 and his MSc in 2013 in hydrology and remote sensing/GIS from the University of Sind, Jamshoro, and NUST, respectively. His current research interests include remote sensing, GIS, and geosciences. 